\title{
Erratum to: Histochemical changes of occlusal surface enamel of permanent teeth, where dental caries is questionable vs sound enamel surfaces
}

\author{
M. Michalaki ${ }^{1}$ C. J. Oulis ${ }^{1}$ - N. Pandis ${ }^{2,3}$ - G. Eliades ${ }^{4}$
}

Published online: 10 January 2017

(C) European Academy of Paediatric Dentistry 2016

\section{Erratum to: Eur Arch Paediatr Dent (2016) \\ 17:445-454 \\ DOI 10.1007/s40368-016-0252-x}

Owing to oversights during the production process, this article appeared with low-resolution versions of the figures. The authors and the publishers apologize for the inconvenience to readers and are pleased to provide the high-resolution figures here.

The online version of the original article can be found under doi:10.1007/s40368-016-0252-x.

M. Michalaki

mmichal@dent.uoa.gr; mgmichalaki@yahoo.gr

1 Department of Paediatric Dentistry, School of Dentistry, University of Athens, 2 Thivon Str., Goudi, 11527 Athens, Greece

2 Department of Orthodontics and Dentofacial Orthopedics, School of Dental Medicine/Medical Faculty, University of Bern, Bern, Switzerland

3 Corfu, Greece

4 Department of Biomaterials, School of Dentistry, University of Athens, 2 ThivonStr, Goudi, 11527 Athens, Greece 

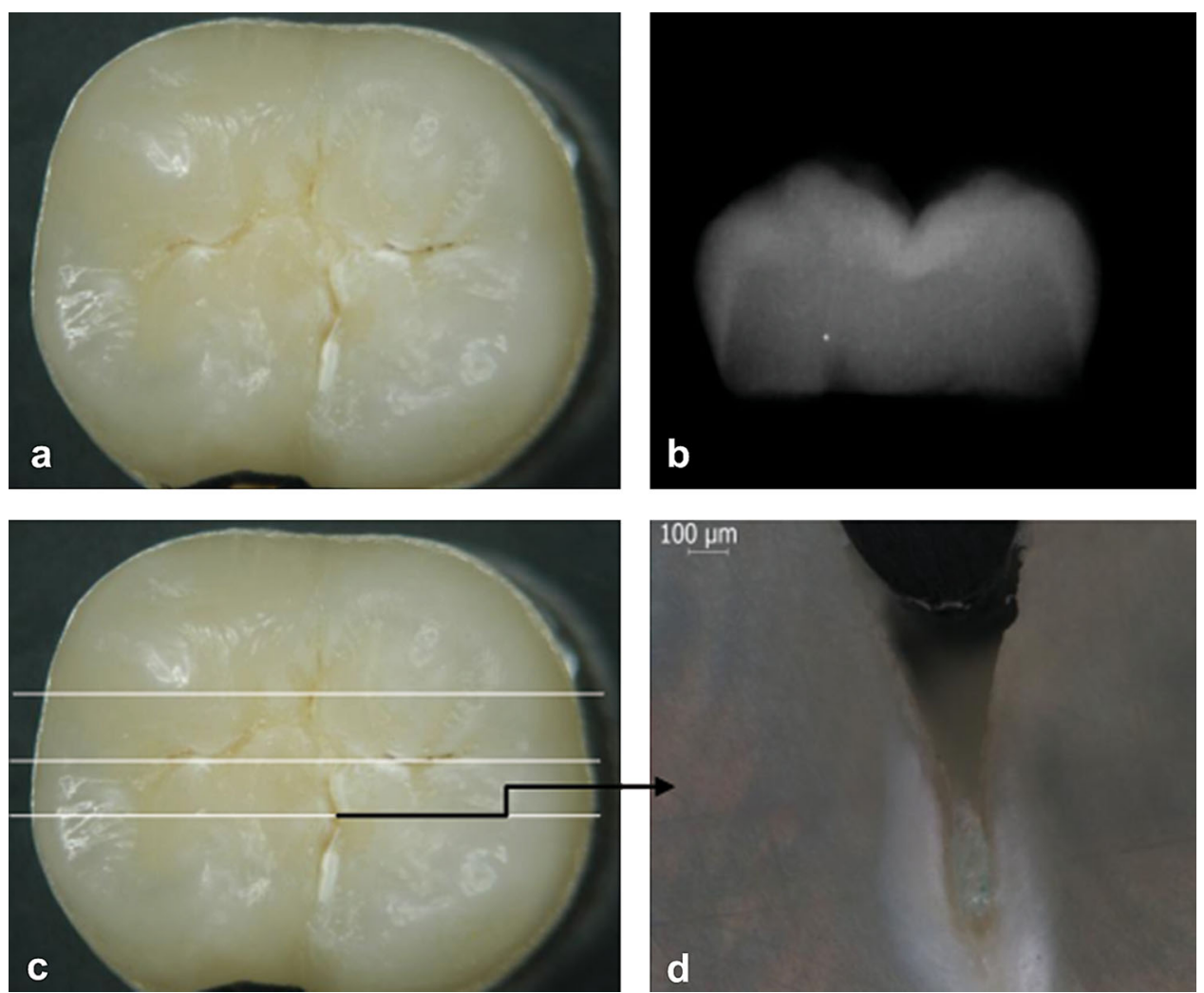

Fig. 1 Questionable surface with ICADS II code 1: a stereomicroscopic image of the occlusal surface, b radiograph of the crown, $\mathbf{c}$ sectioning directions, and $\mathbf{d}$ section image by reflected polarised light microscopy 

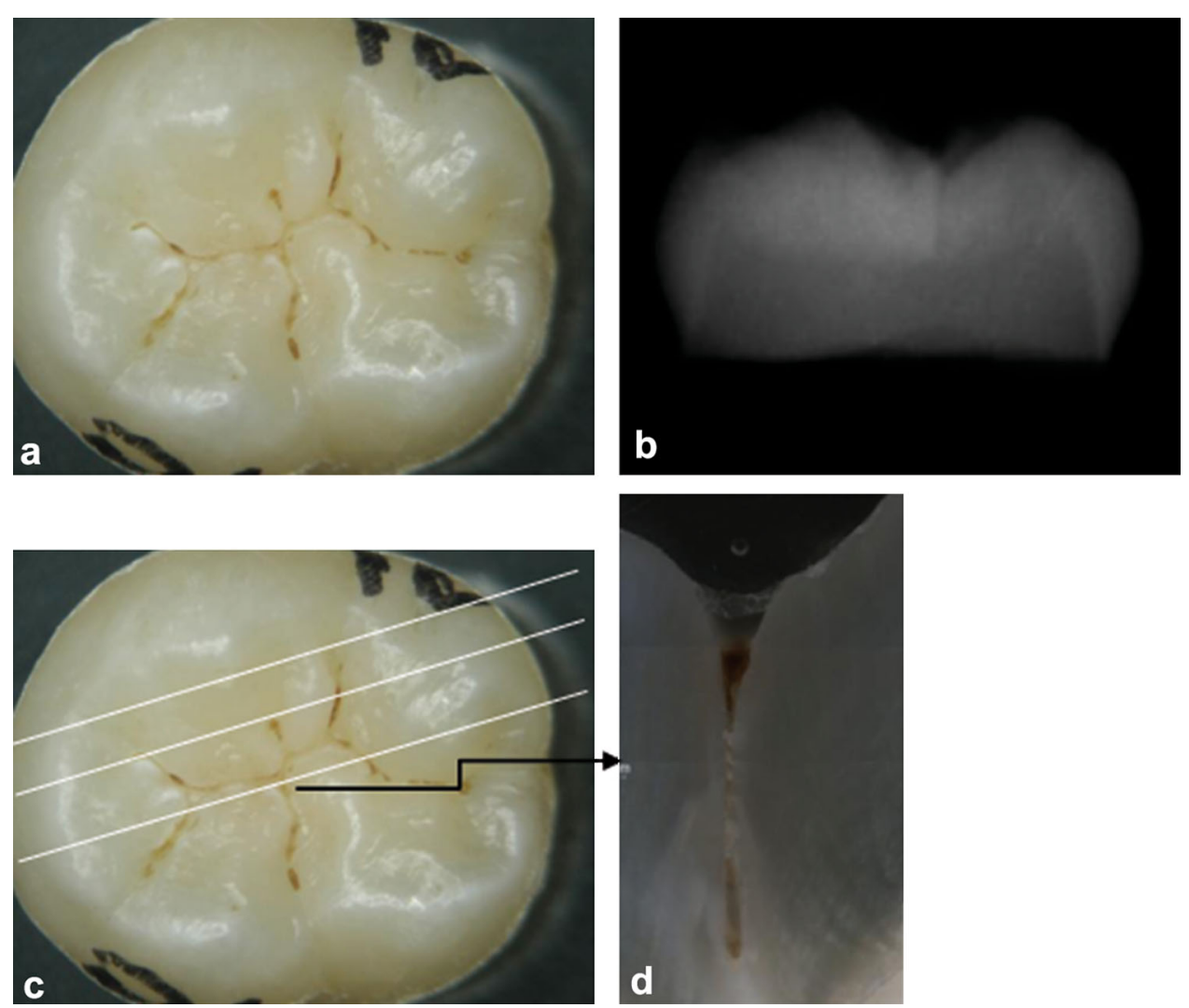

Fig. 2 Questionable surface with ICADS II code 2: a stereomicroscopic image of the occlusal surface, b radiograph of the crown, $\mathbf{c}$ sectioning directions, and $\mathbf{d}$ section image by reflected polarised light microscopy 

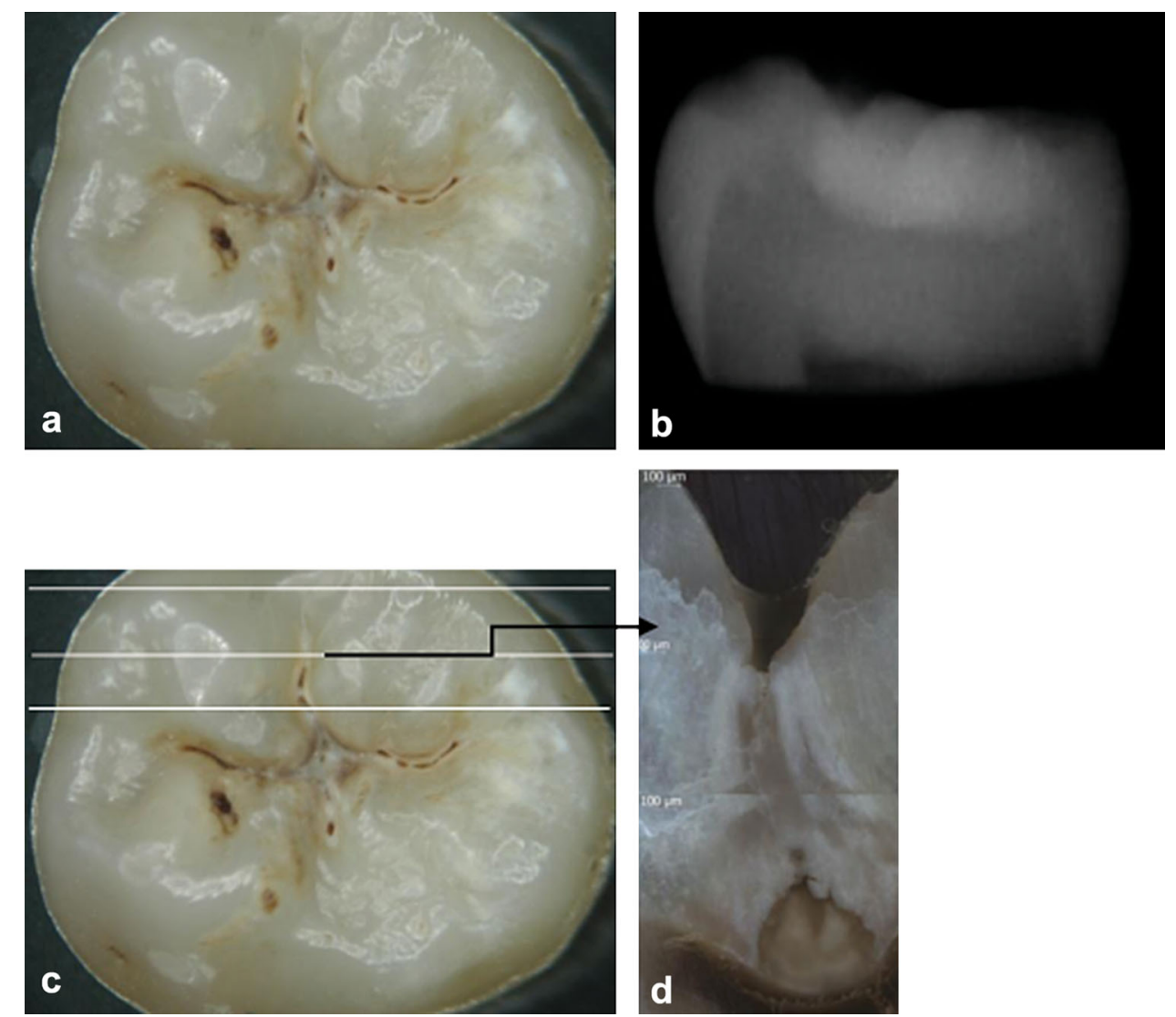

Fig. 3 Questionable surface with ICADS II code 3: a stereomicroscopic image of the occlusal surface, b radiograph of the crown, $\mathbf{c}$ sectioning directions, and $\mathbf{d}$ section image by reflected polarised light microscopy 